\title{
Temperature Field Analysis and Process Control Strategies for MgO Single Crystal Production Using Adaptive Neuro-Fuzzy Inference System
}

\author{
Tie $\mathrm{Li}^{*}$, Zhen Wang and Ninghui Wang \\ School of Electrical Engineering, Dalian University of Technology, China
}

\begin{abstract}
To grow high-purity and large sizes $\mathrm{MgO}$ single crystals with twin-electrode DC submerged arc furnace requires that the temperature distribution be well understood and the processing temperature be precisely controlled. For the complexity of the production of $\mathrm{MgO}$ single crystals and the difficulty to measure the temperature inside the furnace, the temperature distribution was studied by using finite element method (FEM), and the temperature control was realized by the process control strategies with adaptive neuro-fuzzy inference system (ANFIS). Experiments were carried out to verify the effectiveness of the method. The result of experiments indicated that using the adaptive neuro-fuzzy control system can improve the quality and the quantity of the $\mathrm{MgO}$ single crystal production.
\end{abstract}

Keywords: Finite element analysis, twin-electrode DC submerged arc furnace, temperature field, ANFIS.

\section{INTRODUCTION}

The ability of the twin-electrode DC submerged arc furnace to process fines, its increased power efficiency, and its lower electrode consumption have made it popular in crystal growth since its introduction in the late 1970s [1]. The twin-electrode DC submerged arc furnace can easily generate temperature up to $3600^{\circ} \mathrm{C}$ in a short time. Because Magnesium oxide is well known refractory material which has very high melting points, nowadays using twin-electrode DC submerged arc furnace has become the main method applied to grow large magnesium oxide $(\mathrm{MgO})$ single crystals.

The process of $\mathrm{MgO}$ single crystals production can be divided into three stages. The first stage is meltdown stage. In this stage the fundamental task is to get desired size of molten pool in $\mathrm{MgO}$ powder. In order to supply sufficient electric power for the rapid melting of $\mathrm{MgO}$, the $\mathrm{DC}$ voltage of the convertor should be high and the gap between the electrodes should be small. The second stage is refining stage. In this stage the main work is to keep the stability of the molten pool and refine the $\mathrm{MgO}$ melt, so the $\mathrm{DC}$ voltage should be stepped-down and the gap between the electrodes should be increased. The third stage is crystallization stage. In this stage the core job is to build a relatively stable temperature gradient for the crystal growth. In order to decrease the supply of electric power for the growth of $\mathrm{MgO}$ single crystals, the DC voltage should be stepped-down and the gap between the electrodes should be reduced. The supply of the electric power will be shut down until the temperature in the twin-electrode DC submerged arc furnace reach about $2200^{\circ} \mathrm{C}$.

*Address correspondence to this author at the School of Electrical Engineering, Dalian University of Technology, China;

Tel: +86-411-84706489; Fax: +86-411-84706489; E-mails: listeel@yeah.net
With the development of computing power and numerical techniques, the computer modeling of global heat transfer, defect dynamics, and three-dimensional (3D) phenomena for crystal growth has made significant progresses [2]. Finite element method (FEM) was used to predict the temperature distribution.

To keep the stability of the molten pool and build proper temperature gradient in the twin-electrode DC submerged arc furnace is crucial to grow high-purity $\mathrm{MgO}$ single crystals with large sizes. For the process of the $\mathrm{MgO}$ melting is complicated, and the mechanism of single crystals growth is not clearly known, there are a lot of uncertain factors in the production of $\mathrm{MgO}$ single crystals. There have been quite a few researches done both in modeling and simulation of the steel making furnace by the use of conventional and intelligent methods such as fuzzy logic (FL), artificial neural networks (ANN) and neuro-fuzzy systems, an amalgamation of FL and ANN [3]. However, the process of production of $\mathrm{MgO}$ single crystals is quite different from steel making. It is necessary to build a temperature controller with intelligent methods such as adaptive neuro-fuzzy inference system (ANFIS) for the twin-electrode DC submerged arc furnace.

For the complexity of the production of $\mathrm{MgO}$ single crystals and the difficulty to measure the temperature inside the furnace, in this paper, firstly finite element method (FEM) was used to study the temperature field distributions, and then a temperature controller with adaptive neuro-fuzzy inference system (ANFIS) was developed based on the result of the study of FEM and practical experiences. When the temperature in the twin-electrode DC submerged arc furnace was changed, the controller would regulate the positions of three-phase electrodes and the voltage of the power simultaneously. The result of experiments indicated that using the adaptive neuro fuzzy control system can improve the quality and the quantity of the $\mathrm{MgO}$ single crystal production, and through the control of the furnace current, the power quality was improved including power impact and harmonic currents. 


\section{ANALYSIS OF THE TEMPERATURE DISTRI- BUTION OF TWIN-ELECTRODE DC SUBMERGED ARC FURNACE}

\subsection{Mathematic Model of Twin-Electrode DC Submerged Arc Furnace}

The electric arc is the main thermal source of the twinelectrode DC submerged arc furnace. The V-A characters of the arc can be expressed as

$U_{f}=U_{x h}+I_{f} R$

where $U_{f}$ is arc voltage; $I_{f}$ is arc current; $R$ is arc equivalent resistance;

$R$ can be calculated by

$R=\rho k d /\left(k \pi d^{2}\right)$

where $\rho$ is resistivity of submerge-arc determined by experiments; $d$ is diameter of the electrode; the arc length is $k d, k$ is proportionality coefficient; Then $R$ can be seen as the resistance of the arc whose length is $k d$, and section area is $k \pi d^{2}$ 。

Given equation [1] through [2],

$U f=U x h+b l$

In equation (3), $l$ is arc length, $b$ is arc voltage coefficient, determined by experiments; $U x h$ is extinction voltage, determined by the material of electrode, about $14 \mathrm{~V}$ 。

It is assumed that the arc distribution is normal. When one arc goes from the center of one electrode and reaches to the other electrode, it forms an arc spot on the surface of the electrode. The heat flux can be expressed as

$q(r)=q_{m} \bullet e^{-k r^{2}}$

where $q_{m}$ is the heat flux of the arc spot; $k$ is the distance coefficient; $r$ is the distance from the arc spot [4].

Assumed that the radius of arc spot $r H=R+2 l$, and the heat flux $q(r H)=0.05 q_{\mathrm{m}}$, then $k=3(R+2 l)^{-2}$. The energy distribution of any spot can be expressed as

$q_{1}(r)=\frac{3 k_{1} P_{1}^{\prime}}{\pi(R+2 l)^{2}} \cdot e^{\left(\frac{-3 r^{2}}{(R+2 l)^{2}}\right)}$

where $P_{1}^{\prime}$ is the arc power of one electrode; $k_{1}$ is the thermal conductance coefficient.

The molten pool resistance ' $r$ ' is also a significant parameter for modeling the twin-electrode DC submerged arc furnace. For a spot whose coordinate is $(\mathrm{x}, \mathrm{y}, \mathrm{z})$, assumed that the area of the spot is $d x \times d y$, the conductance can be described as

$G^{\prime}=d x d y /(\rho d)$

where $\mathrm{d}$ is distance between the spot and the center of the electrode.

The current passed through the spot can be described as

$i=I \times G^{\prime} / G$
Obviously, The molten pool resistance ' $\mathrm{r} 2$ ' can be obtained by

$G=\iiint G^{\prime} d x d y d z$

The electric energy of the spot inside the molten pool is given as

$q_{2}(x, y, z)=i^{2} r^{\prime}=I^{2} \cdot G^{\prime} / G^{2}$

The energy distribution in molten pool has the form

$Q=q 1+q 2$

where $\mathrm{q} 1$ is calculated according to equation (5) and $\mathrm{q} 2$ is calculated according to equation (7).

The equation of temperature distribution in molten pool is written as

$\frac{\partial}{\partial \mathrm{x}}\left(c \frac{\partial T}{\partial x}\right)+\frac{\partial}{\partial \mathrm{y}}\left(c \frac{\partial T}{\partial y}\right)+\frac{\partial}{\partial \mathrm{z}}\left(c \frac{\partial T}{\partial z}\right)+\mathrm{Q}=0$

where $\mathrm{T}$ is temperature, $\mathrm{c}$ is conductivity coefficient。

\subsection{Thermal Analysis by FEM}

A finite element (FE) thermal model was developed to determine temperature distribution in an twin-electrode DC submerged arc furnace during normal operation [5]. The commercial simulation software ANSYS was used to carry out the FE simulation. The mesh of the model used for 3D simulations was shown in Fig. (1). The information for the analysis, mainly including geometry, working conditions and process parameters were presented in Table 1 . The thermal conductivity of $\mathrm{MgO}$ powder was assigned as a function of temperature which was presented in Table 2. Fig. (2) showed the simulated temperature contours for transverse crosssection of the twin-electrode DC submerged arc furnace, and Fig. (3) showed the simulated temperature contours for longitudinal cross-section of the twin-electrode DC submerged arc furnace. Fig. (4) showed the molten pool near the electrodes during preparation process of $\mathrm{MgO}$ singe crystal.

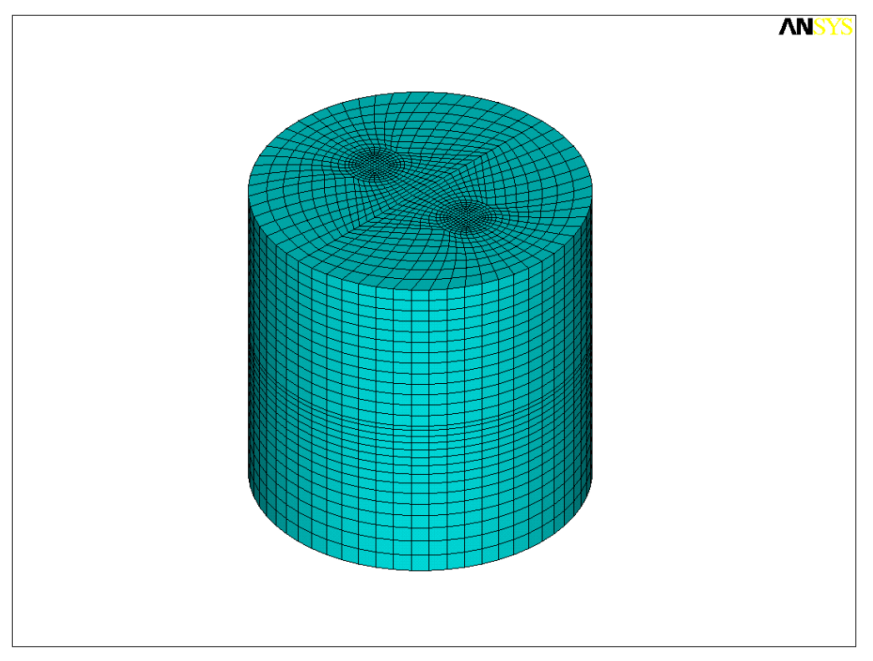

Fig. (1). Finite element mesh for thermal analysis of twin-electrode DC submerged arc furnace. 
Table 1. Characteristics of Work Electrodes and MgO Single Crystal Furnace

\begin{tabular}{|l|l|}
\hline Characteristic & Value \\
\hline \hline Electrode length, $m$ & 2.4 \\
Electrode diameter, $m$ & 0.35 \\
The distance between electrodes center $(\mathrm{mm})$ & 750 \\
Voltage of the output of DC convertor, $V$ & 72 \\
DC current passing the electrodes, $A$ & 6500 \\
Temperature of the furnace atmosphere, $K$ & 400 \\
Ambient temperature, $K$ & 398 \\
Convection coefficient for furnace wall, $W$ m-2 K-1 & 110 \\
Convection coefficient for ambient air, $W$ m-2 K-1 & 10 \\
\hline
\end{tabular}

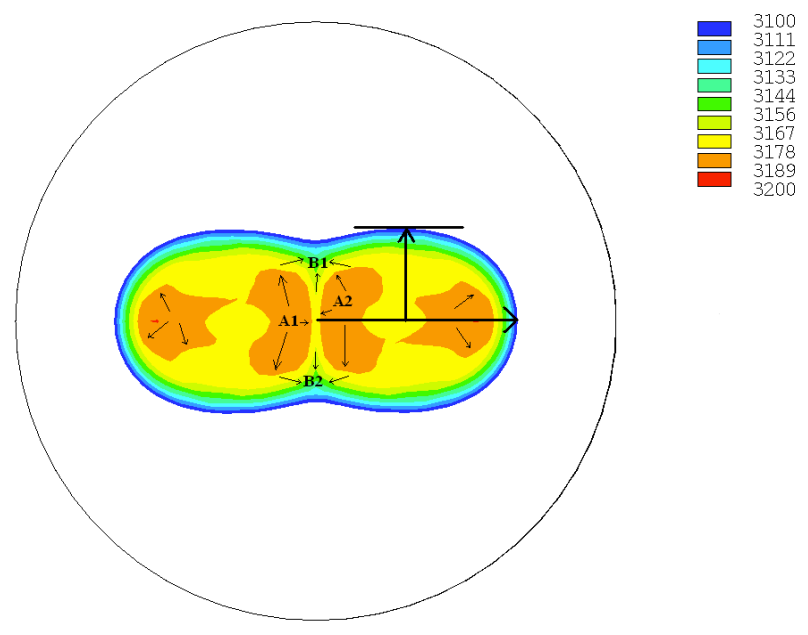

Fig. (2). Simulated temperature contours for transverse crosssection of the furnace, the arrow indicated the direction of the mass transfer.

Some conclusions can be drawn from the comparison between simulated results and practical work.
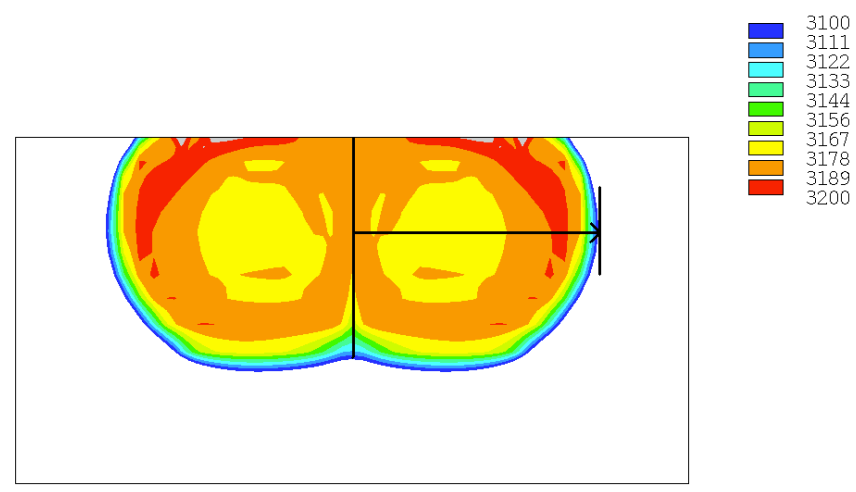

Fig. (3). Simulated temperature contours for longitudinal crosssection of the furnace.

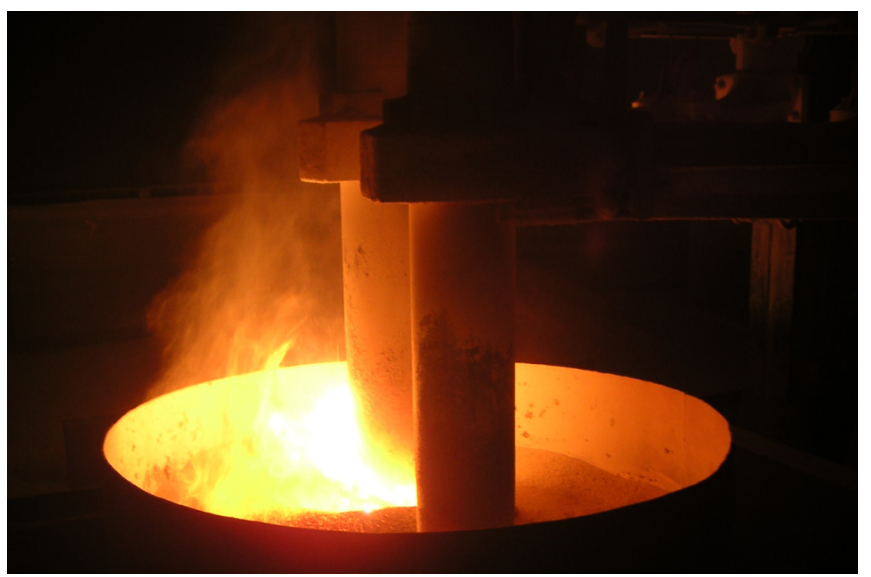

Fig. (4). Photograph of molten pool during melting process.

A) The temperature was highest under the electrodes, and the temperature gradient outside the regions quickly descended with increasing distance. The $\mathrm{MgO}$ powder got the best smelted here, but the dissipation was also highest in these regions.

B) In the regions of A1 and A2, the temperature gradient was the steepest. The material in the molten pool was

Table 2. Thermal Conductivity of MgO Powder

\begin{tabular}{|c|c|c|c|c|}
\hline \multirow{5}{*}{ Solid Powder } & 600 & 47.630 & 13280 & \\
\hline & 1000 & 50.949 & 33104 & \\
\hline & 1400 & 52.763 & 53865 & \\
\hline & 2200 & 55.621 & 97250 & \\
\hline & 2600 & 56.943 & 119763 & \\
\hline \multirow[t]{3}{*}{ Crystals } & 2800 & 57.594 & 131217 & \\
\hline & 3000 & 58.240 & 142801 & \\
\hline & 3098 & 58.556 & 148524 & \\
\hline
\end{tabular}


driven outward by the temperature difference. The arrow indicated the direction of the mass transfer. For the melting point of impurities were lower, they melt to liquid in advance of $\mathrm{MgO}$ powder and moved up to the surface of the molted pool. This made the surface of the molten pool mainly formed by impurities. The regions of $\mathrm{A} 1$ and $\mathrm{A} 2$ were the hot spots of the molten pool, the $\mathrm{MgO}$ powder was well smelted and refined here.

C) In the regions of B1 and B2, the temperature gradient was gentle. The arrow indicated the direction of the mass transfer. For the force of temperature difference was low, these regions were cold spots of the molten pool. Here the $\mathrm{MgO}$ powder could not get well smelted and refined.

D) The temperature gradient descended with increasing depth in the interior of the molten pool. There was a temperature peak in the central of the region, but the temperatures at the periphery of the molten pool were low and very closed. This indicated that the fluidity of the melt was impaired with increasing depth in the interior of the molten pool.

\section{ANFIS MODELING}

An adaptive neuro-fuzzy controller for the preparation of $\mathrm{MgO}$ single crystal was constructed based on the results of the study of FEM and practical experiences. ANFIS is a fuzzy system which is often used in classification, modeling and solving control problems. It is based on Takagi and Sugeno model fuzzy if-then rules representation [6], which is different from commonly used fuzzy logic controllers $[7,8]$. The consequent part of the rule is a function of input variables. The inference mechanism of ANFIS is mathematically expressed by the set of the rules. The schematic diagram of the system was shown in Fig. (5).

The control of the electrodes movements and the regulation of the output voltage of the DC convertor were directly related to the arc current between the electrodes and the $\mathrm{MgO}$ powder. It was central to the control system of the twin-electrode DC submerged arc furnace and affected the temperature gradient distribution in the furnace.

In the Fig. (5), Tr was the set value of temperature, and Ta was the measured value of temperature of the furnace. Subtraction of $\mathrm{Ta}$ from $\mathrm{Tr}$ yielded $\Delta \mathrm{T}$, which was known as deviation signal, i.e., the difference between the set value and the actual value of temperature. $\mathrm{I}_{\mathrm{A}}$ was the operation current of the system. The fuzzy controller had two input terminals, $\Delta \mathrm{T}$ and $\mathrm{I}_{\mathrm{A}} \cdot \mathrm{S}_{\mathrm{A}}$ and $\mathrm{U}_{\mathrm{A}}$ were the outputs of the fuzzy controller, which were converted to analog by $\mathrm{D} / \mathrm{A}$ converter and keeper. $U_{A}$ was used to adjust the output voltage of the $\mathrm{DC}$ convertor and $\mathrm{S}_{\mathrm{A}}$ was used to regulate the movements of the electrodes [9].

A total of 350 data sets were obtained from the results of the study of FEM and practical experiences. Among them a total of 300 data sets were selected for the purpose of training in ANFIS and the rest 50 data sets were selected for testing purposes after the training was completed in order to verify the accuracy of the predicted values [10].

Next, the genetic-oriented clustering method was applied to the training data sets. The cluster centers determined the number of the fuzzy sets and the parameters (mean values) $\mu$ of the membership functions of the antecedent part, as well as the number of fuzzy rules of the Sugeno-type FIS. The standard deviation $\sigma$ was computed as $\sigma=\mathrm{r}_{\mathrm{a}} \cdot 8^{-0.5}$ for all membership functions, where $r_{a}$ was the radius of influence [11]. The number of the resulted clusters for $r_{a}=0.4$ was seven. As a result, each input variable was characterized by seven fuzzy sets with the linguistic values. The consequent parameters of each rule of the Sugeno-type FIS were determined by using the linear least-squares algorithm [12]. The rule base obtained through the genetic-oriented clustering approach consisted of twenty-four rules, shown in Table 3 .

The next step is the training process that aims at tuning the fuzzy inference system. Fig. (6) shows the final

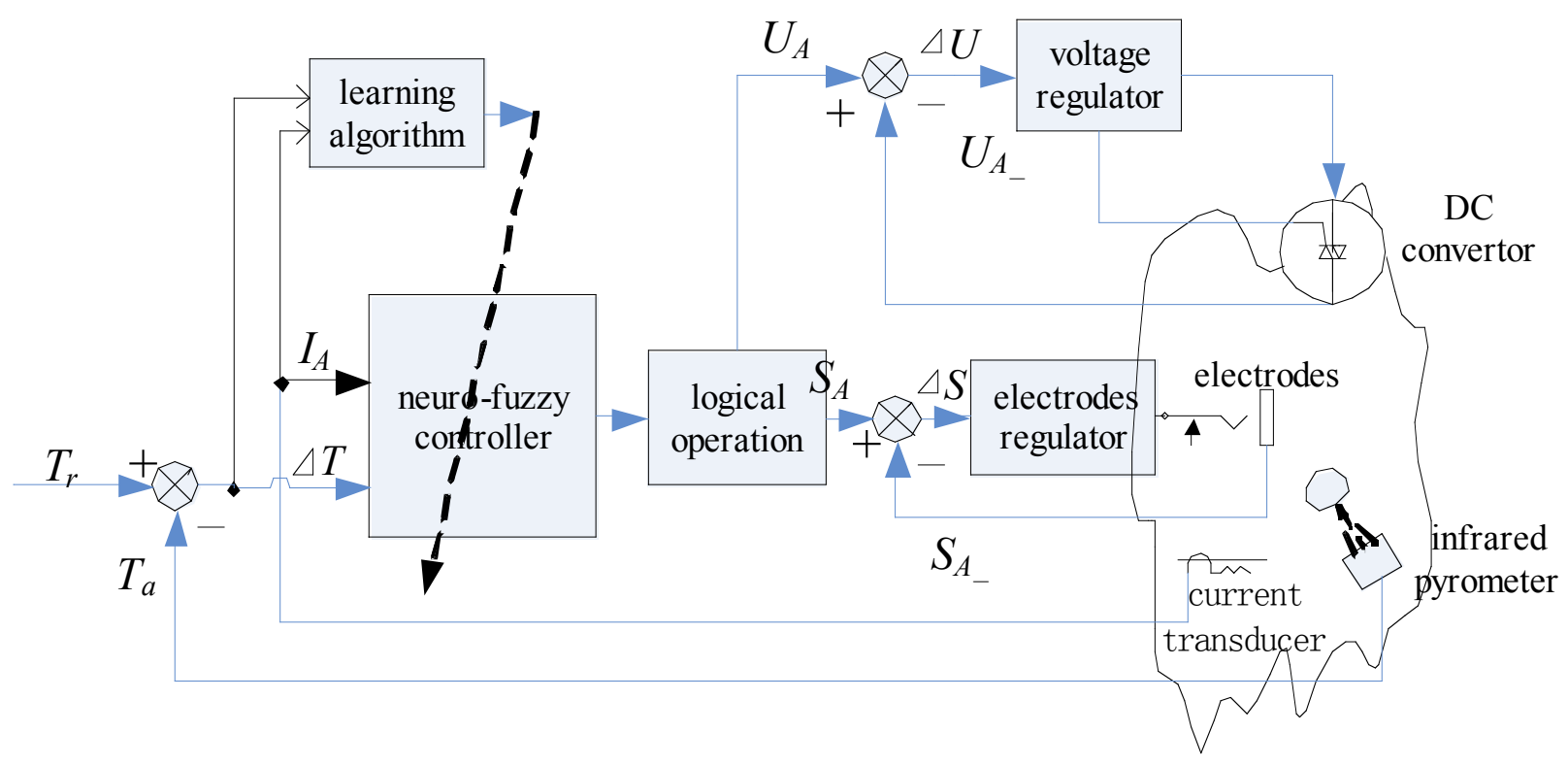

Fig. (5). Schematic diagram of the adaptive neuro-fuzzy inference system. 
(a) Input membership function $\left(I_{A}\right)$

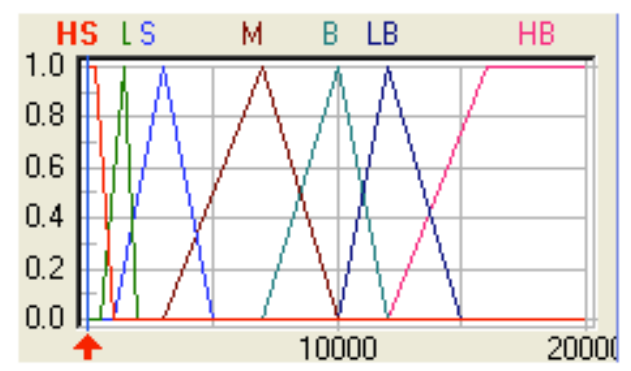

(c) Output membership function $\left(S_{A}\right)$

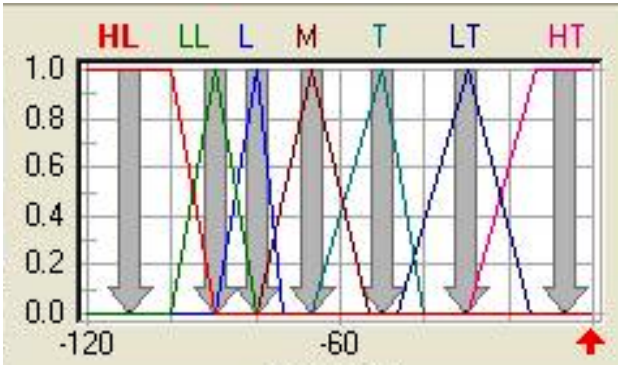

(b) Input membership function ( $\left.\Delta T_{A}\right)$

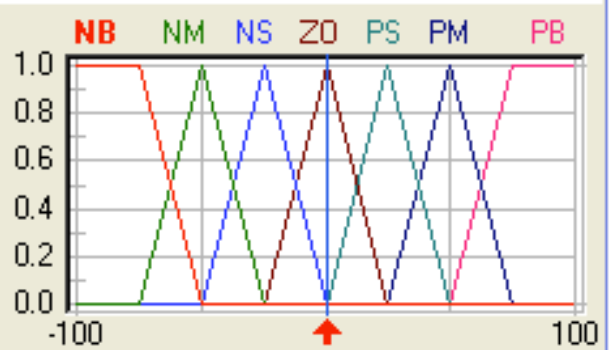

(d) Output membership function $\left(U_{A}\right)$

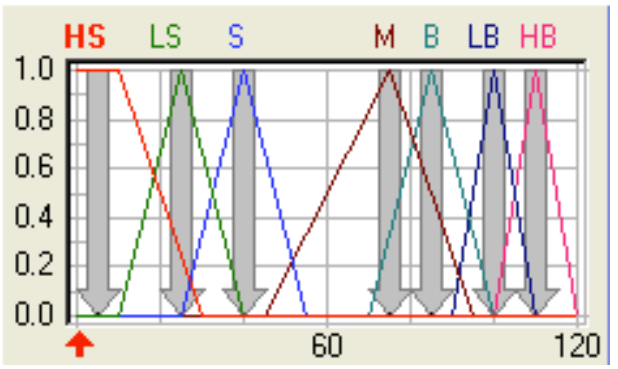

Fig. (6). The final membership functions for input and output after training.

(a) Control surface for $U_{A}$ for different $I_{A}$ and
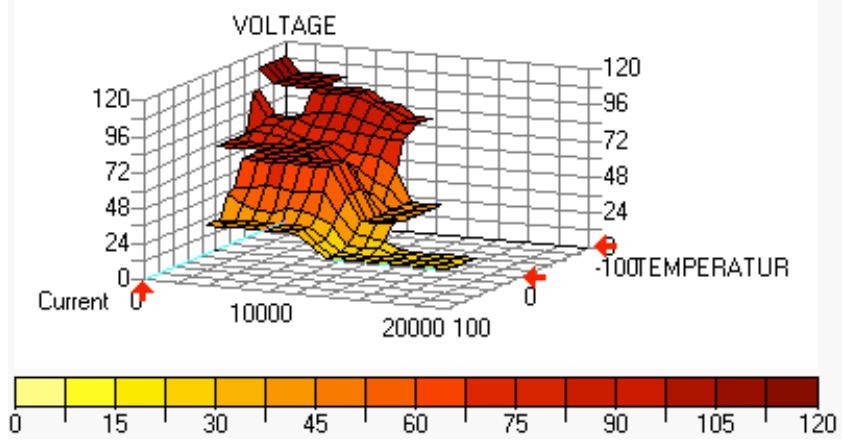

(b) Control surface for $S_{A}$ for different $I_{A}$ and $\Delta T_{A}$

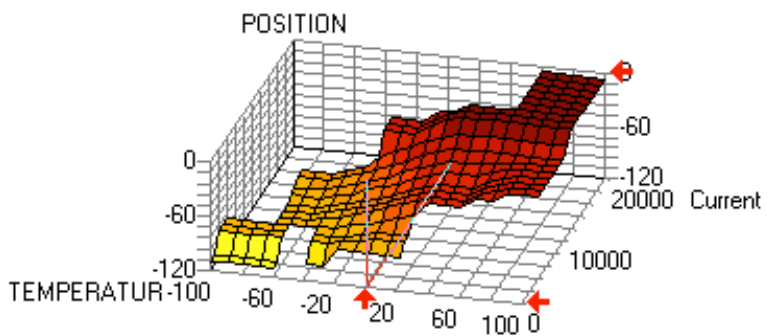

Fig. (7). Three-dimensional plot indicative of the relationship between inputs and outputs.

membership functions derived from the training system. In contrast to the first input, there is a considerable change in the final membership functions concerning the second input, since the supports of all fuzzy sets are broadened. Fig. (7) depicts a three-dimensional plot that represents the mapping from the furnace current and the temperature error to the electrodes position and the output voltage of the DC convertor. The surface has a good continuity as it is normally expected from a Sugeno-fuzzy controller.

\section{Table 3. Fuzzy Rule Base}
(1) If $I_{A}$ is $\mathrm{HS}$ and $\Delta T_{A}$ is NB then $S_{A}$ is $\mathrm{HL}$ and $U_{A}$ is $\mathrm{HB}$ or
(2) If $I_{A}$ is HS and $\Delta T_{A}$ is NM then $S_{A}$ is LL and $U_{A}$ is LB or
(3) If $I_{A}$ is HS and $\Delta T_{A}$ is NS then $S_{A}$ is $\mathrm{L}$ and $U_{A}$ is B or
...... or
(4) If $I_{A}$ is $\mathrm{HB}$ and $\Delta T_{A}$ is PB then $S_{A}$ is NB and $U_{A}$ is HS

Fig. (8) compared the current characters of the preparation system for different control systems with experiments. The capability of restraining the disturbulances of current was greatly improved by using adaptive control system instead of PID control system, which can be proved by the fact that with ANFIS the magnitude of arc current fluctuation was only about one of fourteen with PID. Fig. (8) also showed that the current fluctuated wildly at the beginning, but trended towards stabilization with time going by. This indicated that the adaptive neuro-fuzzy controller need to be optimized at the beginning section of the preparation.

The temperatures of the furnace external shell measured by the adaptive neuro-fuzzy controller were showed in Fig. (9). The temperature rose slowly with time going by, and tended to be stable at last. The maximum temperature of the furnace external shell was lower than $750^{\circ} \mathrm{C}$, this was in good agreement with the result estimated by FEM and avoided the shell overheating.

\section{EXPERIMENTS AND DISCUSSION}

To verify the effectiveness of the adaptive neuro-fuzzy controller for the preparation of $\mathrm{MgO}$ single crystal, experiments were carried out in Liaoning Zhongda Superconducting Material CO., Ltd. The controller comprised a industrial PC which equipped with a single PXI- 
6259 card, a Minolta/Land Cyclops 152 infrared pyrometer, one Halmar current transducers (Lem-Dynamp Corp., Grove City, Ohio), one voltage sensor and a position measuring potentiometer. The NI software LabView was installed on the PC. The analog output from sensors were conditioned and fed into analog input channels of the PXI-6259. Controlled by fuzzy Vi of the NI software LabView, the control signal was converted to an analog signal and sent out using one of the D/A channels on the PXI-6259 card to regulate the positions of two electrodes and the voltage of the power $[13,14]$.

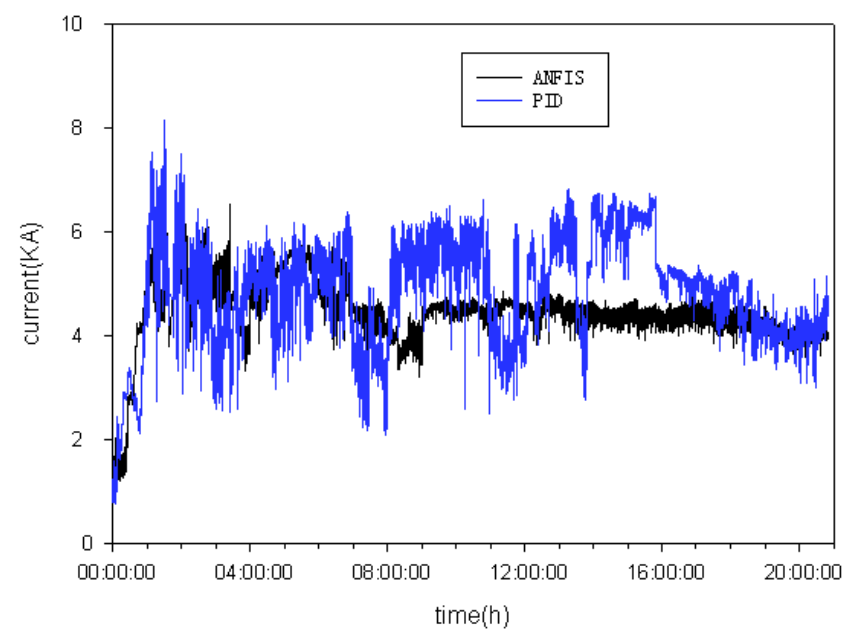

Fig. (8). Comparison of working current between using adaptive neuro-fuzzy inference system and PID control system.

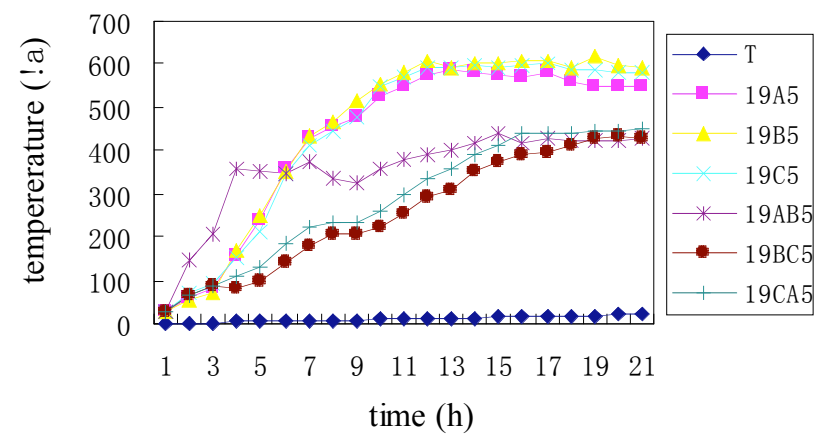

Fig. (9). Distribution diagram of the temperature of temperaturemeasured points on the external shell of the furnace using adaptive neuro-fuzzy inference system.

Numerous growth experiments had been performed using the $\mathrm{MgO}$ powder. $\mathrm{MgO}$ single crystals had been grown by the use of the adaptive neuro-fuzzy inference system. The preferential direction of the obtained large crystals was the (1 $00)$ direction, which was validated by previous work.

X-ray powder diffraction (XRD, D/Max 2400, Rigaku, by a diffractometer equipped with the graphitemonochromatized $\mathrm{CuK} \alpha$ radiation) was employed to analyze the crystalline structure of large $\mathrm{MgO}$ crystals in the $2 \theta$ angles ranging from $2^{\circ}$ to $85^{\circ}$ after the obtained $\mathrm{MgO}$ single crystals were ground into ultra-fine powders.

The XRD pattern of powders of the large $\mathrm{MgO}$ single crystal grown by the adaptive neuro-fuzzy inference system was shown in Fig. (10). All the reflections of the sample can be readily indexed as a pure cubic phase of the $\mathrm{MgO}$ single crystal, which were identical to the reported data in the JCPDS cards (45-0946). The ideal intensity ratio between (220) and (200) was about 0.4 , whereas the measured ratio in this study is smaller than 0.1 . The intensity from the (220) diffraction is strongly depressed.

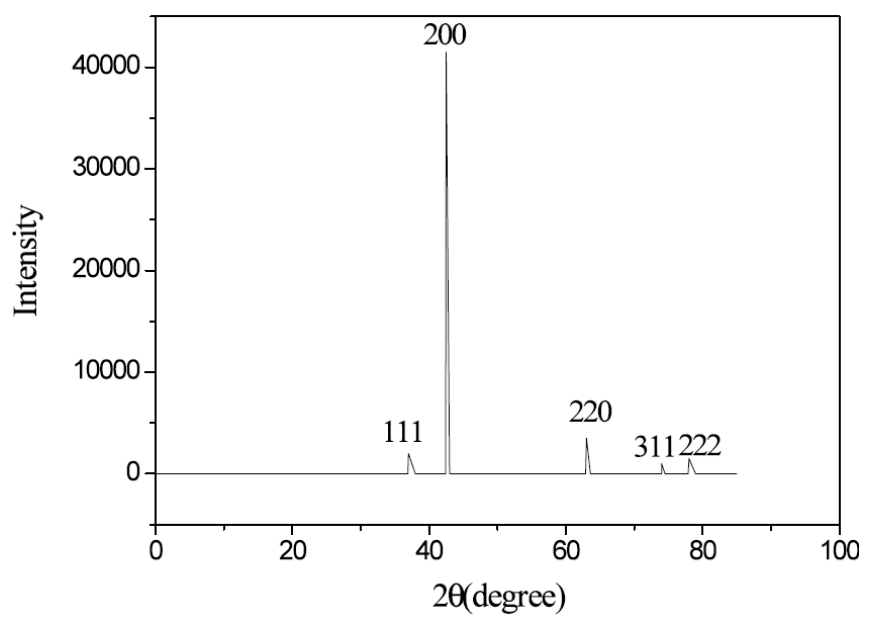

Fig. (10). XRD pattern of the large $\mathrm{MgO}$ single crystal: measured by scan speed $6^{\circ} / \mathrm{min}$ and step interval is $0.020^{\circ}$.

Fig. (11) presents optical absorption spectra of large $\mathrm{MgO}$ single crystals in UV-VIS-NIR wavelength at room temperature. $\mathrm{MgO}$ single crystal possesses a steep absorption edge in the UV region (about 280nm), which means that the strong photoabsorption of these crystals occurs only at wavelengths shorter than $280 \mathrm{~nm}$.

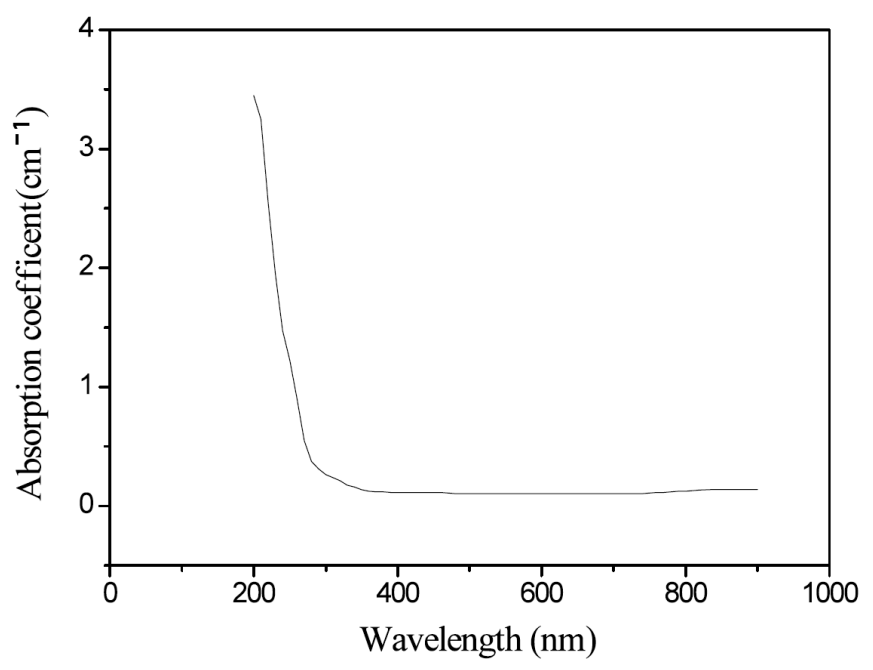

Fig. (11). Optical absorption spectra of $\mathrm{MgO}$ single crystals in the UV-VIS-NIR region.

The ICP-AES analytical technique is a non-destructive analytical method which uses no chemicals for dissolution. It can achieve the detection limits below $0.01 \mathrm{ppm}$ level for most of the impurity elements and it can also be used to trace impurity elements quantity in the crude as well as refined $\mathrm{MgO}$ powder. ICP-AES results are summarized in Table 4.

From the table you can see the overall purity of $\mathrm{MgO}$ single crystal was increased from $99 \%$ to $99.99 \%$. In case of $\mathrm{MgO}$ melting, $96 \%$ of total $\mathrm{Ca}, \mathrm{Al}$, and $\mathrm{Fe}$ impurities were removed. On the same lines, the metallic impurities were 
reduced by $99 \%$ when compared to the initial impurities in crude $\mathrm{MgO}$ powder. ICP-AES analysis results of the $\mathrm{MgO}$ single crystals showed excellent removal effect of interstitial and metallic impurities due to the fact that the high temperature helped in better vaporization of metallic impurities as well as interstitial gases.

Table 4. ICP-AES Results of the MgO Crystal

\begin{tabular}{|c|c|c|c|}
\hline \multicolumn{2}{|c|}{ Items } & Testing Value & ICP Wave-Length \\
\hline \hline \multirow{3}{*}{} & $\mathrm{Al}$ & $2 \mathrm{ppm}$ & 396.153 \\
\cline { 2 - 4 } & $\mathrm{Ca}$ & $32 \mathrm{ppm}$ & 317.933 \\
\cline { 2 - 4 } & $\mathrm{Si}$ & 0 & 251.611 \\
\cline { 2 - 4 } & $\mathrm{Fe}$ & $18 \mathrm{ppm}$ & 238.204 \\
\cline { 2 - 4 } & $\mathrm{Na}$ & $46 \mathrm{ppm}$ & 589.592 \\
\cline { 2 - 4 } & $\mathrm{K}$ & $30 \mathrm{ppm}$ & 766.490 \\
\hline
\end{tabular}

Fig. (12) showed the production of the $\mathrm{MgO}$ single crystals. Fig. (13) showed the surface map of the $\mathrm{MgO}$ single crystal which had been cut and polished. The average size of the single crystals was about $6-8 \mathrm{~cm}$, much bigger than those prepared by manual operation, and the $\mathrm{MgO}$ single crystal output rose from $300 \mathrm{~kg}$ to $800 \mathrm{~kg}$ per heat.

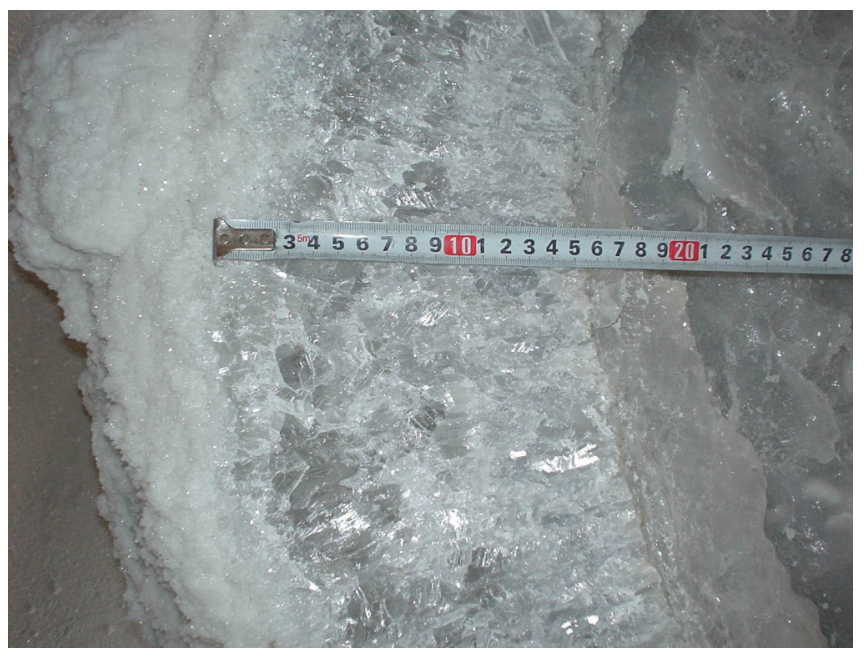

Fig. (12). Photograph of the large $\mathrm{MgO}$ single crystal grown using adaptive neuro-fuzzy inference system.

\section{CONCLUSIONS}

FEM was effective to study the temperature distribution in the preparation process of $\mathrm{MgO}$ single crystal. The temperature in the furnace could be precisely estimated according to the time of operation and process parameters by FEM. This would help to study the single crystal growth theory of $\mathrm{MgO}$, and proposed evidences to the process control of preparation of $\mathrm{MgO}$ singe crystal. Based on the results of the study of FEM and practical experiences, a temperature controller with adaptive neuro-fuzzy inference system (ANFIS) was developed to regulate the positions of two electrodes and the voltage of the power. The result of experiments proved that using the adaptive neuro fuzzy control system can improve the quality and the quantity of the $\mathrm{MgO}$ single crystal production. It indicated that the temperature controller with ANFIS was suitable to control the preparation process of $\mathrm{MgO}$ singe crystal.

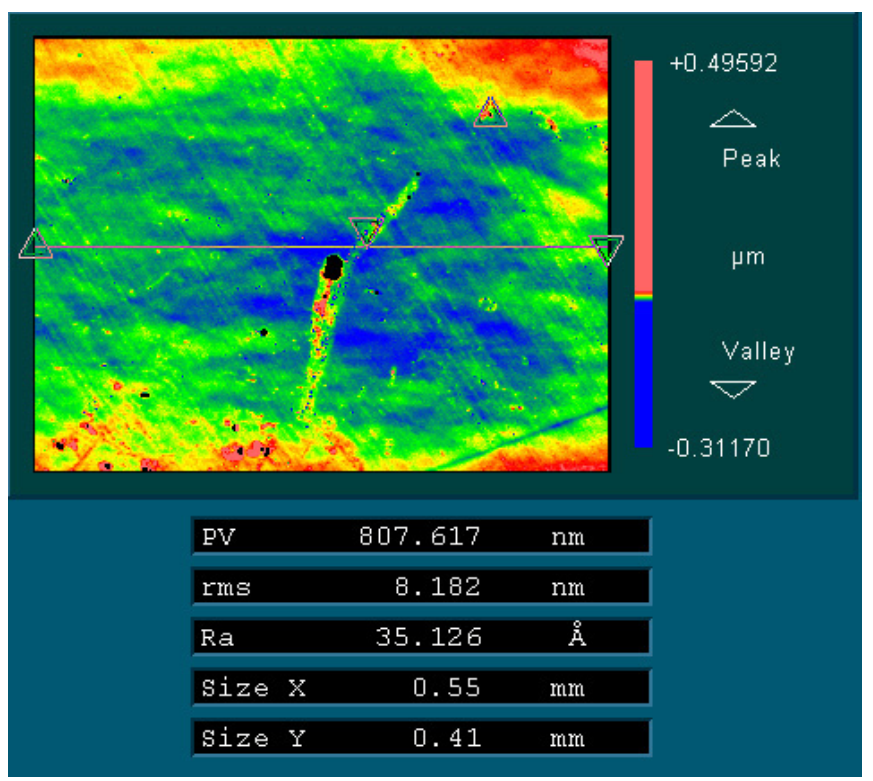

Fig. (13). Surface map of the $\mathrm{MgO}$ single crystal after cut and polished.

\section{ACKNOWLEDGEMENTS}

This work was financially supported by National Natural Science Foundation of China No.2008AA03A325 and by a Hundred Talents Project of Chinese Academy of Sciences.

\section{REFERENCES}

[1] $\mathrm{Xu}$ Zhang. Improved growth technology of large $\mathrm{MgO}$ single crystals. J Cryst Growth 2006; 292: 505-9.

[2] Muller G. Challenges in modeling of bulk crystal growth. J Cryst Growth 2004; 266: 1-19.

[3] Manuel. Online estimation of electric arc furnace tap temperature by using fuzzy neural networks. Eng Appl Artif Intell 2008; 21: 1001-2.

[4] Wang F. Fluid Flow Modeling of Arc Plasma and Bath Circulation in DC Electric Arc Furnace. J Iron Steel Res 2006; 13 : 7-13.

[5] Kumar A. Comparative leakage field analysis of electromagnetic devices using finite element and fuzzy methods. Expert Syst Appl 2010; 27: 3827-34.

[6] Zheng T, Makram EB. An adaptive arc furnace model. IEEE Transactions on Power Delivery 2000; 15: 931-40.

[7] Jang J-SR. Input selection for ANFIS learning. In Proceedings of the IEEE International Conference on Fuzzy Systems. New Orleans, LA, USA 1996.

[8] Janabi-Sharifi F, Jorjani G. An adaptive system for modelling and simulation of electrical arc furnaces. Control Engineer Practice 2009; 17: 1202-19.

[9] Anupam D, Maiti J. Process control strategies for a steel making furnace using ANN with bayesian regularization and ANFIS. Expert Systems with Applications 2010; 37: 1075-85.

[10] Dinh NQ, Afzulpurkar NV. Neuro-fuzzy MIMO nonlinear control for ceramic roller kiln. Simulation Modelling Practice and Theory 2007; 15: 1239-58.

[11] Ekmekci I, Yetisken Y, Camdali U. Mass balance modeling for electric arc furnace and ladle furnace system in steelmaking facility in Turkey. J Iron Steel Res 2007; 14: 1-6. 
[12] Elmas C, Ustun O, Sayan HH. A neuro-fuzzy controller for speed control of a permanent magnet synchronous motor drive. Expert Syst Appl 2008; 34: 657-64.

[13] Horng, JH. Hybrid MATLAB and LabVIEW with neural network to implement a SCADA system of AC servo motor. Adv Eng Software 2008; 39: 149-55.
[14] Huang SN, Tan KK, Lee TH. Adaptive neural network algorithm for control design of rigid-link electrically driven robots. Neuro computing 2008; 71: 885-94.

Received: April 11, 2011

Revised: June 2, 2011

Accepted: June 2, 2011

(C) Li et al.; Licensee Bentham Open.

This is an open access article licensed under the terms of the Creative Commons Attribution Non-Commercial License (http://creativecommons.org/licenses/by-nc/3.0/) which permits unrestricted, non-commercial use, distribution and reproduction in any medium, provided the work is properly cited. 